\title{
A biodigestão como ferramenta para a sustentabilidade avícola - uma revisão
}

\author{
Biodigestion as a tool for poultry sustainability - a review \\ La biodigestión como herramienta para la sostenibilidad de las aves de corral: una revisión
}

Recebido: 30/08/2021 | Revisado: 09/09/2021 | Aceito: 10/09/2021 | Publicado: 12/09/2021

\author{
Karoline Carvalho Dornelas \\ ORCID: https://orcid.org/0000-0003-3780-913X \\ Universidade Federal de Mato Grosso, Brasil \\ E-mail: karolcdornelas@gmail.com \\ Roselene Maria Schneider \\ ORCID: https://orcid.org/0000-0002-3167-5997 \\ Universidade Federal de Mato Grosso, Brasil \\ E-mail: roselenems@yahoo.com.br \\ Adriana Garcia do Amaral \\ ORCID: https://orcid.org/0000-0002-5641-8583 \\ Universidade Federal de Mato Grosso, Brasil \\ E-mail: adrianagamaral@gmail.com \\ Ana Paula Silva Ton \\ ORCID: https://orcid.org/0000-0002-5826-1874 \\ Universidade Federal de Mato Grosso, Brasil \\ E-mail: anatonn4@hotmail.com \\ Nágela Maria Henrique Mascarenhas \\ ORCID: https://orcid.org/0000-0001-9059-3695 \\ Universidade Federal de Campina Grande, Brasil \\ E-mail:eng.nagelamaria@gmail.com
}

\begin{abstract}
Resumo
A avicultura é uma atividade bem desenvolvida e importante para o Brasil. Porém, é uma atividade geradora resíduos, principalmente os sólidos, como a cama. Como alternativa para reduzir o impacto ambiental e os custos produtivos da atividade, muitos avicultores empregam a reutilização da cama por vários lotes consecutivos. Sabendo-se que a reutilização da cama se dá por alguns lotes apenas, tem-se que é preciso em algum momento realizar o descarte da cama. Uma das possíveis formas para tratamento (redução do risco de poluição) é o processo de biodigestão. Dessa forma, objetivou-se com a execução desta revisão uma abordagem sobre a biodigestão como alternativa para sustentabilidade da avicultura de corte nacional. Utilizou-se como método uma revisão no campo bibliográfico de caráter exploratório sobre o resíduo gerado na atividade, o processo de biodigestão, o emprego de inóculo e os tipos de biodigestores predominantes. Conclui-se que, por meio da biodigestão da cama de frango, o produtor produz combustível para geração de energia a baixo custo, gerencia de forma correta o resíduo da granja, além de colaborar ambientalmente, reduzindo os possíveis impactos ambientais produzidos na atividade avícola, tornando a atividade um modelo de produção sustentável, sem perda de produção de carne.
\end{abstract}

Palavras-chave: Bioenergia; Resíduos de aves; Produção de biogás; Biodigestor; Inóculo.

\begin{abstract}
Poultry is a well-developed and important activity for Brazil. However, it is an activity that generates waste, especially solid ones, such as bedding. As an alternative to reduce the environmental impact and production costs of the activity, many poultry farmers use the reuse of bedding for several consecutive batches. Knowing that the reuse of the bed takes place in a few batches only, it is necessary at some point to carry out the disposal of the bed. One of the possible ways for treatment (reduction of the risk of pollution) is the biodigestion process. Thus, the aim of this review was to approach biodigestion as an alternative for the sustainability of domestic poultry farming. The method used was a review in the bibliographic field of an exploratory nature on the waste generated in the activity, the biodigestion process, the use of inoculum and the predominant types of biodigesters. It is concluded that, through the biodigestion of chicken litter, the producer produces fuel for energy generation at a low cost, correctly manages the farm's waste, in addition to contributing to the environment, reducing the possible environmental impacts produced in the poultry activity, making the activity a sustainable production model, without loss of meat production.
\end{abstract}

Keywords: Bioenergy; Poultry waste; Biogas production; Biodigester; Inoculum.

\section{Resumen}

La avicultura es una actividad bien desarrollada e importante para Brasil. Sin embargo, es una actividad que genera residuos, especialmente sólidos, como la ropa de cama. Como alternativa para reducir el impacto ambiental y los costos de producción de la actividad, muchos avicultores utilizan la reutilización de la ropa de cama para varios lotes 
consecutivos. Sabiendo que la reutilización de la cama se realiza en unos pocos lotes, es necesario en algún momento llevar a cabo la eliminación de la cama. Una de las posibles vías de tratamiento (reducción del riesgo de contaminación) es el proceso de biodigestión. Así, el objetivo de esta revisión fue abordar la biodigestión como una alternativa para la sostenibilidad de la avicultura doméstica. El método utilizado fue una revisión en el campo bibliográfico de carácter exploratorio sobre los residuos generados en la actividad, el proceso de biodigestión, el uso de inóculo y los tipos de biodigestores predominantes. Se concluye que, a través de la biodigestión de la basura de los pollos, el productor produce combustible para la generación de energía a bajo costo, gestiona correctamente los residuos de la finca, además de contribuir al medio ambiente, reduciendo los posibles impactos ambientales producidos en la actividad avícola, haciendo la actividad un modelo de producción sostenible, sin pérdida de producción de carne.

Palabras clave: Bioenergía; Residuos de aves de corral; Producción de biogás; Biodigestor; Inóculo.

\section{Introdução}

No cenário de produção animal para corte, o setor da avicultura apresenta crescimento ano após ano. No ranking mundial de exportações de frangos de corte o Brasil ocupa o primeiro lugar desde 2004 e em termos de produção mundial situa-se como o terceiro país, atrás apenas dos Estados Unidos da América e China (Abpa, 2021). Em 2020 as exportações brasileiras de frangos alcançaram 4.231 milhões de toneladas exportadas. Do volume total de frangos produzido pelo país em 2020, $69 \%$ foram destinados ao consumo interno, e $31 \%$ para exportações. Com isto, o consumo per capita de carne de frango atingiu 45,21 quilos ano-1 (Abpa, 2021).

Esse aumento da produção de frangos de corte faz com que haja o acréscimo no volume de resíduos gerados na atividade (Paiva et al., 2012; Garcês et al., 2017; Ribeiro et al., 2018). Os resíduos provenientes da exploração avícola se caracterizam pelas carcaças de aves mortas e, principalmente, a cama (Garcês et al., 2017). A cama de frangos é um material absorvente distribuído sobre a pavimentação dos galpões que serve de leito às aves, material este, que ao final do ciclo produtivo será composto ainda por excretas, penas das aves e restos de ração (Suzuki et al., 2012; Garcês et al., 2017).

De acordo com Chinivasagam et al. (2016), como forma de reduzir os custos produtivos, a cama de frangos é reutilizada por vários lotes consecutivos, constituindo dessa forma um resíduo com elevada carga orgânica e consequentemente elevado potencial poluidor. No geral, a reutilização ocorre por seis lotes consecutivos, não devendo, no entanto, ser reutilizado quando o lote anterior houver passado por problemas sanitários (Virtuoso et al., 2015).

Entretanto, quando ocorre a substituição da cama de frangos, a sua remoção se dá, geralmente, considerando a sua aplicação no solo, se houver disponibilidade de área (Nie et al., 2015). Não havendo área para aplicação, por vezes o granjeiro não tem opção, senão descartar o resíduo em áreas disponíveis, comumente próximas a recursos hídricos, originando um passivo ambiental (Font-Palma, 2012; Nie et al., 2015).

A aplicação direta da cama de frangos no solo, sem um tratamento apropriado pode provocar eventos impactantes tanto no solo quanto nos corpos hídricos, culminando com a degradação dos ecossistemas aquáticos e geração de riscos à saúde humana, pois é um material que contém elevada carga orgânica, especialmente nitrogênio e fósforo (Perondi et al., 2017).

Assim sendo, a expansão do setor avícola deve ser analisada tendo como foco tanto os parâmetros de desempenho produtivo e bem-estar animal, quanto às questões ambientais ligadas a atividade, visando preservar o ambiente, visto que, este resíduo apresenta alto potencial poluidor quando gerenciado e descartado de forma incorreta. Nesse contexto, a biodigestão anaeróbia surge como uma alternativa atraente para o tratamento do resíduo avícola.

Esse é um método eficaz no tratamento de dejetos da produção animal, principalmente por reduzir a concentração de micro-organismos patogênicos, melhorar as características agronômicas do material por meio da estabilização da matéria orgânica, além de produzir uma fonte energética alternativa, o biogás (Orrico Júnior et al., 2012; Ge et al., 2014; Zeb et al., 2017). De acordo Oliveira et al. (2011), os nutrientes presentes no resíduo garantem a sobrevivência e reprodução da comunidade microbiológica responsável pela biodigestão do material orgânico, ocorrendo estabilização do resíduo. 
Segundo Nutiu (2014) e Caruso et al. (2019), neste processo de tratamento as bactérias anaeróbias - bactérias que vivem em um ambiente desprovido de oxigênio (biodigestor), degradam a matéria orgânica presente, obtendo como subprodutos biogás e biofertilizante, que podem se tornar fonte de renda e agregar valor à avicultura, além de tornar a atividade um modelo de produção sustentável, pois o biogás pode ser convertido em energia elétrica contribuindo para uma amortização dos custos da tecnologia instalada (Sunada et al., 2012; Suzuki et al., 2014).

O biogás produzido a partir da biodigestão da cama de frangos pode ser aproveitado para o aquecimento dos pintinhos, por meio de simples queimadores a gás, que executam a combustão do biogás e, consequente, produção de calor, imprescindível nas duas primeiras semanas do ciclo produtivo, além de se implantar geradores à biogás para promover o funcionamento dos sistemas de alimentação, iluminação e ventilação das granjas (Sagula et al., 2017). Além do biogás, obtêmse o biofertilizante, que pode ser usado para vários fins, em diferentes tipos de solos, para diversas culturas vegetais e em diferentes estágios de desenvolvimento das plantas, para controle biológico de patógenos de vegetais, para controle de plantas daninhas e para recuperação de solos danificados.

Segundo Colatto e Langer (2011), o processo de biodigestão estabiliza o efluente final (biofertilizante), fornecendo substrato com baixa relação carbono/nitrogênio devido à perda de carbono sob a forma de metano $\left(\mathrm{CH}_{4}\right)$ e pH entre 6,5 e 7,5. O biofertilizante oriundo do processo de biodigestão apresenta todos os nutrientes presentes no dejeto fresco, mas exposto na forma estável e prontamente disponível para as plantas, sendo uma alternativa viável em relação aos fertilizantes minerais.

Ou seja, por meio da biodigestão da cama de frangos, o produtor produz combustível para geração de energia a baixo custo, gerencia de forma correta o resíduo da granja obtendo adubo orgânico, além de colaborar ambientalmente, reduzindo os possíveis impactos ambientais produzidos na atividade avícola (Luste et al., 2012; Silva et al., 2013). Outras vantagens do emprego da biodigestão no meio rural são o controle de odores e a diminuição da emissão de gases.

Diante do exposto, objetiva-se com essa revisão realizar uma abordagem sobre a biodigestão da cama de frango como uma alternativa para a sustentabilidade do setor, avaliando o potencial de produção de biogás e biofertilizante frente a diferentes números de reutilizações da cama.

\section{Metodologia}

Esta revisão de literatura de caráter exploratório e informativo (Pereira et al., 2018) apresenta uma explanação de forma abrangente de como o processo de biodigestão pode constituir uma solução alternativa para destinação da cama de frango, principal resíduo decorrente da atividade avícola, bem como seu potencial para produção de biogás e biofertilizante, abrangendo uma compilação de ideias no campo bibliográfico.

Realizou-se uma busca de trabalhos correlatos ao assunto proposto, selecionando-se de forma criteriosa artigos e trabalhos científicos de impacto que abordam a referente temática (Pereira et al., 2018). Os artigos selecionados para elaboração do presente trabalho foram retirados dos respectivos bancos de dados: Elsevier, Google Acadêmico, Periódicos Capes, Pubmed, Scielo, Scopus e Science Direct, na qual foram elaboradas sínteses de conhecimento prioritário entre os artigos da decante corrente (2011-2021), sem desconsiderar os trabalhos relevantes de anos anteriores.

\section{Produção de Frangos de Corte - Panorama Nacional}

A indústria de criação de frangos (avicultura) cresce rapidamente para atender à crescente demanda global da sociedade para alimentos saudáveis e nutritivos (Purnomo et al., 2017). A avicultura de corte brasileira possui grande representação mundial (Procópio \& Lima, 2020) e impressiona pelo seu dinamismo e pela competência (Tremea \& Silva, 2020), destacando-se como o maior exportador mundial de carne de frango, exportando para todos os continentes, e terceiro maior produtor do setor avícola (Tremea \& Silva, 2020), registrando em 2020 uma produção de 13,845 milhões de toneladas 
de frangos (Abpa, 2021).

A produção de frangos de corte em escala industrial no Brasil iniciou posteriormente a Segunda Guerra Mundial. Os estados mais desenvolvidos até meados da década de 1960 foram os que se destacaram na avicultura - São Paulo, Rio de Janeiro e Minas Gerais (Tremea \& Silva, 2020). Em meados de 1960 os programas de melhoramento genético passaram a avaliar o número de ovos incubáveis e a taxa de eclosão, entre 1970 e 1980, a preocupação voltou-se para a conversão alimentar e no início dos anos 1990, as pesquisas passaram a incluir as instalações de equipamentos, expressando preocupação com a redução de mão de obra e o bem-estar animal (Schmidt \& Silva, 2018).

Essas características foram ganhando importância com o aumento das exigências sanitárias, tanto em âmbito nacional como internacional, e as novas normativas voltadas para a preservação do meio ambiente, aliado a isso, as grandes modificações no sistema produtivo, destacando-se o alto nível tecnológico e a integração avicultor/agroindústria, deram maior dinamismo à atividade, colocando-a em posição privilegiada em relação a outras atividades pecuárias no Brasil (Schmidt \& Silva, 2018; Procópio \& Lima, 2020). Para os produtores, o sistema de integração garante o escoamento da produção e assistência técnica, obtenção de melhores insumos de produção, assegura produção ininterrupta, propicia maior facilidade de acesso ao crédito e a incorporação mais rápida de inovações tecnológicas (Oliveira et al., 2015).

Como consequência, nossa produção tem sido uma das mais organizadas do mundo, destacando-se das demais criações pelos resultados alcançados não só em produtividade e volume de abate, como também no desempenho econômico, onde tem contribuído de forma significativa para a economia brasileira (Procópio \& Lima, 2020). Outro fator favorável à criação de frangos no Brasil é a elevada produção interna de grãos como o milho e a soja, principais matérias-primas da alimentação das aves (Procópio \& Lima, 2020).

Em termos gerais, pode-se afirmar que os avanços da avicultura brasileira foram resultados da introdução de inovações nas áreas de genética, nutrição, sanidade e novos equipamentos no sistema criatório, o que possibilitou um ganho significativo na taxa de conversão alimentar (Schmidt \& Silva, 2018). Atualmente a exploração avícola tem se caracterizado pela produção de frangos de corte cada vez mais precoces, o que constitui um dos ramos da produção animal de maior desenvolvimento e progresso tecnológico (Reck \& Schultz; 2016).

Os estados que apresentaram as maiores taxas de crescimento na produção de carne avícola no país no período compreendido entre 2011 e 2018 foram Mato Grosso com 66,57\%, seguido do Pará (63,04\%), Mato Grosso do Sul (53,24\%), Maranhão (52,76\%), Roraima (42,09\%), Goiás (35,71\%) e Paraná (28,41\%) (Procópio \& Lima, 2020). Considerando-se a acirrada competição global no mercado de carne de frango, é indispensável que a cadeia continue com uma postura para buscar soluções que atendam às novas e constantes demandas (Bortolini et al.,2020). Essa atitude também permeia a preocupação com a sanidade, que perpassa todos os elos da cadeia (Schmidt \& Silva, 2018).

\section{Resíduos da Produção de Frangos de Corte}

O crescimento do setor representa melhorias para os produtores, consumidores e para toda economia do país, no entanto, este crescimento de produção também tem acarretado maior volume de resíduos sólidos produzidos (Perondi et al., 2017). Dessa forma, implementar soluções para o manejo adequado dos resíduos são indispensáveis para assegurar a preservação ambiental.

Dentro dos resíduos produzidos, o principal subproduto da produção avícola é a cama (Bortolini et al.,2020). A cama de frango é constituída pelas excretas (fezes e urina) e pelo material empregado como substrato, com a finalidade de receber e absorver a umidade proveniente dessas excretas, bem como as penas e descamações da pele das aves, e os restos de alimento e água que caem dos sistemas de alimentação, proporcionar isolamento térmico e uma superfície confortável para as aves, 
evitando contato direto com o piso para impedir a formação de calosidade no peito das aves, fator importante diante da nobreza deste corte (Taupe et al.,2016).

É importante ressaltar, que as camas não são iguais, existe uma variação nos materiais, como casca de arroz, maravalha, casca de amendoim, bem como variação nas quantidades utilizadas como substrato para formação dessa cama, variando também os números de lotes que são criados sobre a mesma cama (Garcês et al., 2017). O material que constitui a cama geralmente é um subproduto abundante na região (Perondi et al., 2017).

A quantidade da cama de frango, bem como suas características físicas e químicas, depende de vários fatores, entre eles pode-se destacar a duração do lote, a densidade de alojamento (aves $\mathrm{m}^{-2}$ ), número de reutilizações da cama, tipo de manejo, características ambientais da região, entre outros (Taupe et al., 2016). Dalólio et al. (2017) estimam que a produção de cama para um ciclo de 42 dias de criação varia de 1,5 a $5,7 \mathrm{~kg}$ de cama ave $\mathrm{e}^{-1}$.

A aplicação direta da cama de frangos no solo, sem um tratamento apropriado pode provocar eventos impactantes tanto no solo quanto nos corpos hídricos, proporcionando, consequentemente, a degradação dos ecossistemas aquáticos e gerando riscos à saúde humana, especialmente pelos seguintes fatos: primeiramente por conter uma grande carga orgânica e, em segundo lugar, pela enorme quantidade de nitrogênio e fósforo que estão presentes nos dejetos (Perondi et al., 2017; Bayrakdar et al., 2018). Segundo Taupe et al. (2016), a contaminação do solo e da água comprometem a qualidade dos mesmos, além de proporcionar, em alguns casos, toxicidade a animais e plantas, fatos estes que só serão observados a médio e longo prazo.

Além da geração excessiva de resíduos, a atividade ainda consome uma grande quantidade de energia elétrica para manter o sistema de alimentação, ventilação e aquecimento das aves. Para Catarino et al. (2009), os gastos com energia elétrica podem contribuir com até $60 \%$ dos custos de produção. A partir dessas informações pode-se observar que a produção de frangos de corte apresenta dois entraves: altos gastos com energia elétrica e geração de resíduos.

Dessa forma, programar e implementar soluções para o manejo adequado do resíduo são indispensáveis para assegurar a preservação ambiental em todo país. A possibilidade de incorporar aos sistemas de produção animal - no caso dos frangos de corte - conceitos de desenvolvimento sustentável e preservação dos ecossistemas é algo necessário, de certa forma até mandatório (Purnomo et al., 2017). A sustentabilidade dos mais variados sistemas de produção e as validações de tecnologias que diminuam os riscos ambientais são ações que cooperam para uma melhor qualidade de vida não só dos produtores rurais, mas também de toda uma sociedade (Purnomo et al., 2017).

É necessário desenvolver um sistema de manejo adequado do resíduo avícola de tal modo que viabilize a aplicação na agricultura, mitigando os riscos ambientais. A cama constitui resíduo com potencial para ser utilizado como fertilizante, com macro e micronutrientes provenientes das excretas das aves (Purnomo et al., 2017).

\section{Biodigestão da Cama de Frangos}

Os estudos sobre biogás no Brasil foram mais significativos a partir de 1996. Entretanto, os resultados alcançados já naquela época demonstraram um bom domínio tecnológico podendo ser qualificado como apto a desenvolver um vasto programa no âmbito nacional com biogás, tanto no setor agrícola como no setor industrial (Martins \& Assis, 2007).

É de conhecimento, a importância e necessidade de substituição do uso dos combustíveis de origem fóssil por combustíveis de fontes renováveis e que gerem menor impacto ambiental, devido à redução gradual dos combustíveis fósseis, aumento dos custos e instabilidade nos principais países produtores (Fasolin et al., 2014). Entre as opções de combustíveis de fontes renováveis tem-se a energia eólica, solar, hidráulica, biomassa, entre outras. A energia vinda da biomassa, especificamente dos resíduos de origem animal, apresenta amplo potencial energético como combustível, e oferecem uma das melhores alternativas para o desenvolvimento de energia sustentável (Pasqualini, 2020). 
Como a maioria dos sistemas de produção animal utiliza o confinamento, isto proporciona um aumento na densidade dos animais, ou seja, maior número de animais por unidade de área, gerando um maior acúmulo de resíduos (biomassa), matéria prima para geração de energia (Taupe et al., 2016; Pasqualini, 2020). Para Costa (2012) estes sistemas produtivos baseados no confinamento podem contribuir para geração de energia dentro da propriedade, tornando assim o produtor mais independente das fontes externas de energia - autossuficiente.

Como a produção de frangos de corte cresce consideravelmente, e apresenta-se como uma atividade de alto potencial poluidor, isto se agrava com o aumento no número de animais confinados em pequenas áreas, com consequente aumento no volume de dejetos e resíduos produzidos - cama de frango (Taupe et al., 2016). A cama de frango apresenta potencial nutricional significativo, com elevados teores de N, P e K (Paula Junior, 2014), e além de nutrientes, esse resíduo da atividade avícola apresenta valor energético notável (Bayrakdar et al., 2018).

Como resultado, as fontes alternativas de energia têm sido um tema quente de investigação para pesquisadores em todo o mundo. Encontrar fontes de energia limpas, mais seguras e diversificadas pode ser uma estratégia bem-sucedida para reduzir e eliminar as emissões de gases de efeito estufa (GEE) e atender às necessidades mundiais de energia (Hajjaji et al., 2016).

A biodigestão se apresenta como uma ótima alternativa para o tratamento da cama de frango, podendo colaborar com a amortização de parte do custo gerado com a produção avícola (Bayrakdar et al., 2018). Esse é um processo pelo qual bactérias anaeróbias - bactérias que vivem num ambiente desprovido de oxigênio - no caso o biodigestor, degradam a matéria orgânica presente, obtendo como subprodutos biogás e biofertilizante, produtos com alto valor agregado (Sagula, 2012; Paula Junior, 2014; Nutiu, 2014; Caruso et al., 2019; Penteado et al., 2021). Apresentando um processo atrativo tanto na esfera ambiental quanto na social, já que promove a geração de fontes de suprimento energéticas descentralizadas, sendo este um fator essencial para o desenvolvimento sustentável do país (Freitas et al., 2018).

O biogás produzido a partir da biodigestão da cama de frango pode ser aproveitado para o aquecimento dos pintinhos, por meio de simples queimadores a gás, que executam a combustão do biogás e, consequente, produção de calor, imprescindível nas duas primeiras semanas do ciclo produtivo, além de se implantar geradores á biogás para promover o funcionamento dos sistemas de alimentação, iluminação e ventilação das granjas. Com a utilização dos subprodutos, biogás e biofertilizante, o avicultor conseguirá amortizar muitos de seus gastos, tornando-se assim mais competitivo, além de enquadrar-se nas exigências ambientais regionais (Catarino et al., 2009). Ou seja, por meio da biodigestão da cama de frango, o produtor produz combustível para geração de energia a baixo custo, gerencia de forma correta o resíduo da granja, além de colaborar ambientalmente, reduzindo os possíveis impactos ambientais produzidos na atividade avícola (Costa, 2012; Silva et al., 2013). De acordo com Holm-Nielsen et al. (2009), Nges \& Liu (2010) e Sagula (2012) outras vantagens do emprego da biodigestão no meio rural são o controle de odores e a diminuição da emissão de gases.

Na biodigestão os processos biológicos são favorecidos quando se têm temperaturas médias altas (Freitas et al., 2018). Considerando que as temperaturas anuais médias registradas na maior parte do território nacional são elevadas, tem-se que o processo de biodigestão anaeróbia é viável e aplicável durante todo o ano. Como a produção de biogás depende da temperatura operacional do biodigestor, as temperaturas maiores geram produções mais eficientes pelas bactérias metanogênicas (Freitas $e t$ al., 2018). Quedas na temperatura operacional do biodigestor resultam em reduções na produção de biogás, pois retardam o processo. Temperaturas em torno de $15^{\circ} \mathrm{C}$ geram produções relativamente pequenas, e próximas a $10^{\circ} \mathrm{C}$, a produção cai significativamente, podendo até cessar (Freitas et al., 2018).

$\mathrm{O}$ processo no interior dos biodigestores divide-se basicamente em quatro etapas metabólicas, sendo a primeira: hidrólise, seguida pela acidogênese, acetogênese e terminando na metanogênese (Batista et al., 2019; Gonçalves \& Ramalho, 2021; Penteado et al., 2021), conforme apresentado na Figura 1. 
Figura 1. Etapas metabólicas para a produção de metano.

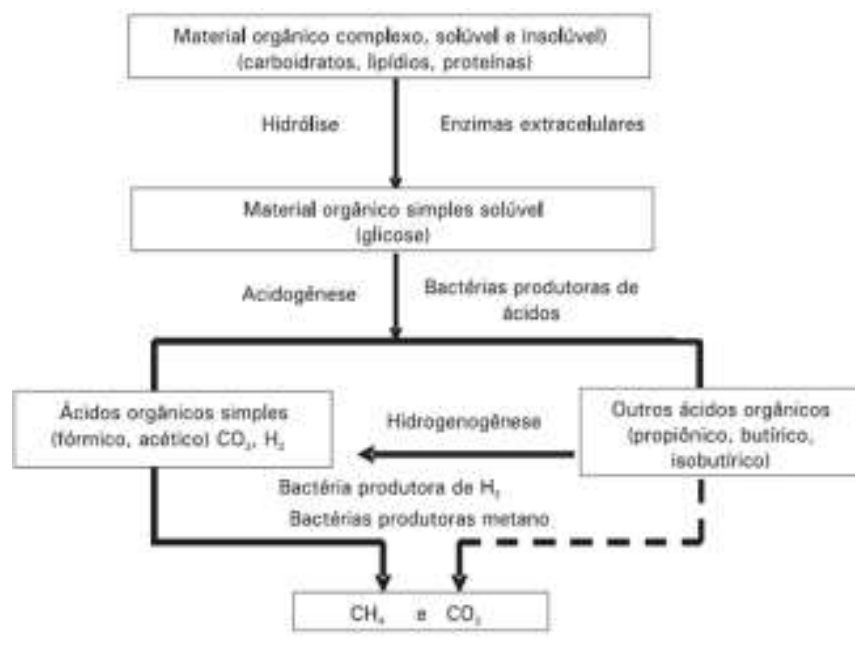

Fonte: Oliveira e Ramalho (2006).

A primeira etapa metabólica envolve bactérias fermentativas, incluindo micro-organismos anaeróbios e facultativos. Nesta fase, as substâncias orgânicas complexas, como por exemplo, carboidratos, proteínas e lipídios, são transformados pela hidrólise em substâncias simples, como álcool, amônia, hidrogênio, ácidos graxos, dióxido de carbono e sulfetos (Gonçalves \& Ramalho, 2021). Na segunda etapa as bactérias fermentativas rompem os subprodutos da fase 1, degradando sua estrutura em ácidos orgânicos e álcoois, bem como gás carbônico e hidrogênio (Gonçalves \& Ramalho, 2021).

A terceira etapa envolve as bactérias acetogênicas, que consomem o material orgânico simples e produzem hidrogênio, dióxido de carbono, ácido acético, entre outros ácidos orgânicos. Por último a etapa metanogênica, em que dois grupos distintos de bactérias metanogênicas participam, produzindo metano e dióxido de carbono (Gonçalves \& Ramalho, 2021).

O grupo das bactérias metanogênicas subdivide-se de acordo com a temperatura do resíduo (Caruso et al., 2019). A faixa ideal para desenvolvimento do grupo das bactérias mesofílicas situa-se entre $20{ }^{\circ} \mathrm{C}$ e $45^{\circ} \mathrm{C}$, já o grupo das bactérias termofílicas se desenvolvem em temperaturas mais elevadas, normalmente acima de $45{ }^{\circ} \mathrm{C}$, sendo o ideal para este grupo valores de $56{ }^{\circ} \mathrm{C}$ (Singh et al., 2016). As termofílicas são as responsáveis pela redução do tempo de retenção hidráulica, pois elas aceleram o processo de digestão do resíduo (Singh et al., 2016).

A composição do biogás varia, especialmente, conforme a temperatura no interior do biodigestor, o resíduo com que é alimentado e o tempo de retenção hidráulica (Caruso et al., 2019). O biogás que é produzido nos biodigestores é constituído basicamente por metano $\left(\mathrm{CH}_{4}\right)$ e dióxido de carbono $\left(\mathrm{CO}_{2}\right)$, além de traços de nitrogênio $\left(\mathrm{N}_{2}\right)$, hidrogênio $\left(\mathrm{H}_{2}\right)$, oxigênio $\left(\mathrm{O}_{2}\right)$ e gás sulfídrico $\left(\mathrm{H}_{2} \mathrm{~S}\right)$ (Leite et al., 2009; Kohn et al., 2014; Patel et al., 2016; Angelidaki et al., 2018; Caruso et al., 2019). A concentração destes gases varia. Brumano (2008) e Wicks et al. (2013) encontraram concentrações variando de 60 a $70 \%$ de $\mathrm{CH}_{4}$ e 30 a $40 \%$ de $\mathrm{CO}_{2}$, para Metz (2013) o $\mathrm{CH}_{4}$ correspondeu a aproximadamente $65 \%$ e o $\mathrm{CO}_{2}$ a $35 \%$ do biogás, os traços de $\mathrm{N}_{2}, \mathrm{H}_{2}, \mathrm{O}_{2}$ e $\mathrm{H}_{2} \mathrm{~S}$ equivaleram ao máximo de $1 \%$. Para Trevizan (2013), de modo geral o biogás é constituído por 54 a $80 \%$ de $\mathrm{CH}_{4}, 20$ a $45 \%$ de $\mathrm{CO}_{2}$ e leves traços de outros gases (Ribeiro et al., 2018). Em termos comparativos, o gás natural possui $88 \%$ de metano.

O biogás gerado pode ser considerado de boa qualidade para se empregar em motores de combustão interna quando apresentar no mínimo uma concentração de $60 \%$ de metano. Valores inferiores implicariam no mau funcionamento do motor, ocasionando falhas no sistema e dificuldades de ignição (Suzuki et al., 2012; Okudoh et al., 2014). Segundo Seman et al. 
(2019) o potencial energético do biogás é dado pelo teor de metano, que confere ao biogás um alto poder calorífico, o qual varia de 22.500 a $25.000 \mathrm{~kJ} \mathrm{~m}^{-3}$, e que, submetido a um alto índice de purificação, pode gerar um índice de até $35.800 \mathrm{~kJ} \mathrm{~m}^{-3}$.

Estudos indicam que há uma linearidade crescente na produção de biogás com a reutilização da cama de frango de corte (Dornelas et al., 2017). Santos (2001), ao realizar biodigestão com substratos de cama de frangos de corte com $15 \%$ de inóculo, obteve biogás com teores de $\mathrm{CH}_{4}$ em torno de 65\%. Aires et al. (2010) encontraram valor de $64,87 \%$ de $\mathrm{CH}_{4}$ ao efetuarem a biodigestão de cama de frangos de corte de $3^{\circ}$ lote de utilização, água e inóculo, com separação da fração sólida, em 21 dias de retenção hidráulica. Dornelas et al. (2017) ao avaliarem o potencial de geração do biogás em biodigestores experimentais a partir de diferentes números de reutilizações do material cama de frangos de corte, observaram um aumento linear no teor de metano (60 a 80\%) com o número de reutilizações (camas reutilizadas de 1 a 4 ciclos).

Do processo de biodigestão resulta também um tipo de biofertilizante, como supracitado, que pode ser utilizado para aumentar a produção e a produtividade das plantações (Ribeiro et al., 2020; Rêgo et al., 2021). Os fertilizantes de modo geral apresentam a função de alimentar as plantas, disponibilizando nutrientes de tal forma que sejam assimilados com mais facilidade pela cultura (Martins \& Assis, 2007; Rêgo et al., 2021). O biofertilizante oriundo do processo de biodigestão apresenta todos os nutrientes presentes no dejeto fresco, mas exposto na forma estável e prontamente disponível para as plantas

(Rêgo et al., 2021). De acordo com Silva \& Abud (2017) e Rêgo et al. (2021), o biofertilizante constitui um adubo orgânico com propriedades nutricionais que melhoram as características físicas, químicas e biológicas do solo, além realizar o papel de proteção às plantas contra pragas e doenças.

Tessaro et al. (2015) ao avaliarem a biodigestão de cama de frango variando a presença de resíduo e água, concluiram que o biofertilizante produzido apresentou macro e micronutrientes assimiláveis por vegetais como nitrogênio, fósforo, potássio, cálcio, magnésio, sódio, ferro, boro, cobre, zinco e manganês.

\section{Utilização de Inoculante na Biodigestão}

O emprego de inoculante na biodigestão anaeróbica consiste em reutilizar uma parcela do material que já passou pela biodigestão e que seja capaz de prover ao novo substrato que irá ser tratado uma população suplementar de micro-organismos característicos do processo (Bortolini et al., 2020).

Segundo Gyenge et al. (2014) e Caruso et al. (2019) a utilização de inoculante no processo de biodigestão proporciona estabilidade no funcionamento do biodigestor, antecipa o pico de produção de biogás, além de elevar a quantidade de micro-organismos presentes no processo e reduzir o 'start' de operação do biodigestor, sendo essenciais principalmente para materiais com alto teor de celulose e lignina, apresentando difícil digestão, como visto na cama de frango (Bortolini et al., 2020).

A quantidade de biogás produzida no processo pode ser influenciada pela fonte de inóculo empregada no processo, assim como influenciar a velocidade da biodigestão (Caruso et al., 2019). É salutar ressaltar que, diferentes inóculos levam a diferentes produções de biogás, com efeito significativo do tipo de inóculo sobre o percentual de metano (Rieze et al., 2015; Caruso et al., 2019). Deste modo, conhecer o inoculante, bem como a comunidade microbiana e seu papel no processo é fundamental para o controle eficaz do processo (Shen \& Zhu, 2016).

Conforme Steil (2002) a quantidade empregada de inóculo interfere nos resultados do biodigestor. $\mathrm{O}$ autor avaliou três concentrações de inóculo $(0,10$ e 15\%) com resíduos de suínos, aves de postura e cama de frangos de corte, e, concluiu que as concentrações de $10 \%$ para resíduos de cama de frangos de corte e aves de postura, e 15\% para resíduos de suínos geraram melhores resultados.

Segundo Aquino et al. (2007) a quantidade inicial de inóculo interfere na duração do processo da biodigestão, sendo que quanto maior for à quantidade de inoculante, mais rápida será a degradação do substrato disponível. Demirci \& Demirer 
(2004) afirmam que o uso de outros resíduos como inoculantes em consórcio com a cama de frangos, podem trazer efeitos benéficos sobre a produção de biogás.

De acordo com Xavier e Lucas Junior (2010) com o uso de inoculante obtido de um biodigestor operado anteriormente com dejetos de vacas leiteiras e cujo tempo de retenção hidráulica foi de 50 dias ocorreu antecipação dos picos de produção de biogás além da diminuição do tempo de retenção hidráulica, quando substratos de dejetos de vacas leiteiras foram tratados em biodigestores do tipo batelada.

Como cita Nogueira 1986 apud Barana (2000), o processo de biodigestão pode ser iniciado de dois modos: com ou sem adição de inóculo rico em bactérias metanogênicas. A grande vantagem da utilização do inóculo no início do processo é a redução do tempo de partida e alcance mais rápido do período de estabilização do biodigestor com produção normal de biogás. Caso não exista inoculação, deve-se alimentar de forma contínua o biodigestor com o substrato a ser tratado, até o alcance da flora bacteriana desejável.

Segundo Dotto e Wolff (2012), resíduos de bovinos são característicos por propiciarem acelerada proliferação das bactérias metanogênicas no processo de biodigestão, proporcionando uma produção de biogás em um espaço de tempo menor do que a produção com dejetos de outros animais. Dessa forma, os autores sugerem que, sempre que possível, seja adicionado resíduo bovino na primeira carga do biodigestor, pois este dejeto equipará, ligeiramente, a quantidade necessária de bactérias metanogênicas que irão digerir os dejetos de outros animais.

O emprego de resíduo bovino no processo produz efeitos sinérgicos, como capacidade de tamponamento devido ao baixo $\mathrm{pH}$, além de fornecer elementos necessários as bactérias metanogênicas necessárias (Rao \& Baral, 2011). Outra vantagem da co-digestão de cama de frango com resíduo bovino é a melhoria da estabilidade do processo anaeróbio devido a um melhor equilíbrio da relação entre carbono e nitrogênio (El-Mashad \& Zhang, 2010).

Abouelenien et al. (2009) obtiveram um incremento de 93\% de metano e Zhang et al. (2014), 73\% com emprego de inoculante em relação a biodigestão isolada da cama de frango.

\section{Biodigestores}

O Brasil possui condições climáticas muito satisfatórias para empregar a energia gerada pelos biodigestores, e aposentar de certa forma os derivados de petróleo, principalmente no meio rural. Com essa alternativa, o Brasil reduziria de forma significativa uma parcela da importação dos derivados de petróleo (Arruda et al., 2002). Além de representar uma alternativa energética, o biodigestor é uma alternativa tecnológica para o tratamento de resíduos no campo, proporcionando um destino adequado aos dejetos da produção animal e amenizando o impacto ambiental causado pela atividade produtiva. Essa alternativa resulta em sustentabilidade, proteção ao meio ambiente, geração de energia limpa, renovável e ganhos ambientais.

Para Santos e Lucas Junior (2004) o emprego dos biodigestores no meio rural tem merecido destaque devido aos aspectos de saneamento e produção de energia, além de estimularem a reciclagem orgânica e de nutrientes. Existem diversos tipos de biodigestores, mas de maneira generalizada, todos são compostos basicamente por dois itens: um tanque que abriga e permite a biodigestão da biomassa, e um gasômetro - campânula que armazena o biogás (Bonturi \& Dijk, 2012). Em relação ao abastecimento de biomassa, o biodigestor pode ser classificado como contínuo, com abastecimento diário e com descarga proporcional à entrada de biomassa, ou intermitente, quando utiliza sua capacidade máxima de armazenamento de biomassa, retendo-a até a completa biodigestão (Neto et al., 2010).

Segundo Batista et al. (2019), os modelos de biodigestores mais empregados nas propriedades rurais brasileiras são os modelos indiano e chinês. De acordo com Deganutti et al. (2004), o modelo de biodigestor indiano distingue-se por conter uma campânula como gasômetro, que pode estar mergulhada em um selo d'água externo ou então, imersa sobre o substrato em fermentação, e uma divisória central que reparte o local de fermentação em duas câmaras. O emprego da mureta divisória no 
biodigestor faz com que o resíduo circule por todo o interior da câmara de fermentação, e o fato do gasômetro estar disposto ou sobre o substrato ou sobre o selo d'água, reduz as perdas durante o processo de produção do gás (Jorge \& Omena, 2012). Nesse modelo, a pressão no interior do biodigestor é mantida constante, pois à medida que o volume de gás gerado não é consumido de imediato, o gasômetro desloca-se verticalmente, aumentando o volume deste, conforme pode ser observado pela Figura 2.

Figura 2. Modelo de biodigestor indiano.

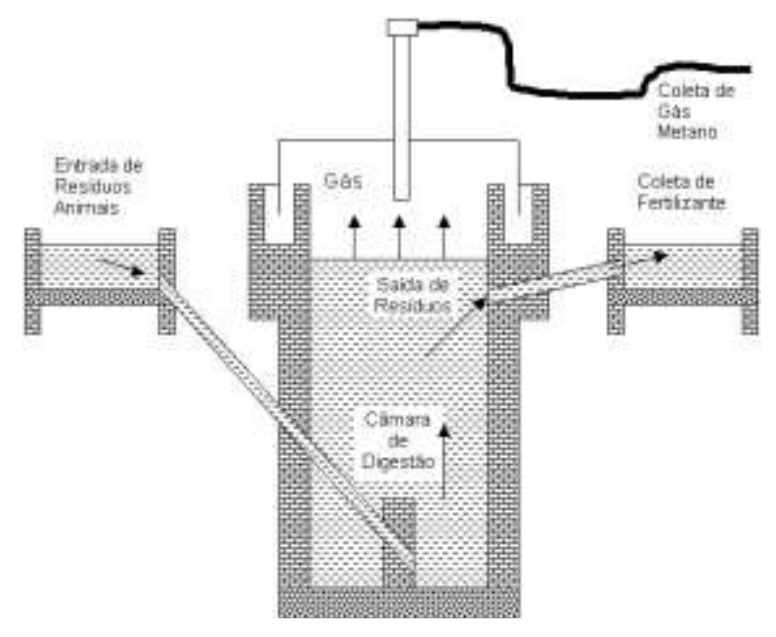

Fonte: Faria (2011).

Já o modelo de biodigestor chinês, apresentado na Figura 3, é composto por uma câmara cilíndrica em alvenaria relativamente baixa, com o teto em formato abobado, destinado ao armazenado do biogás produzido (Jorge \& Omena, 2012). Este biodigestor funciona com base no princípio de prensa hidráulica, evitando desde modo o uso do gasômetro, contudo pode apresentar problemas de vazão de gases caso a estrutura não seja bem vedada e impermeabilizada, deste modo, sua construção requer cuidados no aspecto de impermeabilização. Seu custo geralmente é menor já que o gasômetro onera o custo do biodigestor e apresenta eficiência em instalações de pequeno porte (Deganutti et al., 2004).

Figura 3. Modelo de biodigestor chinês.

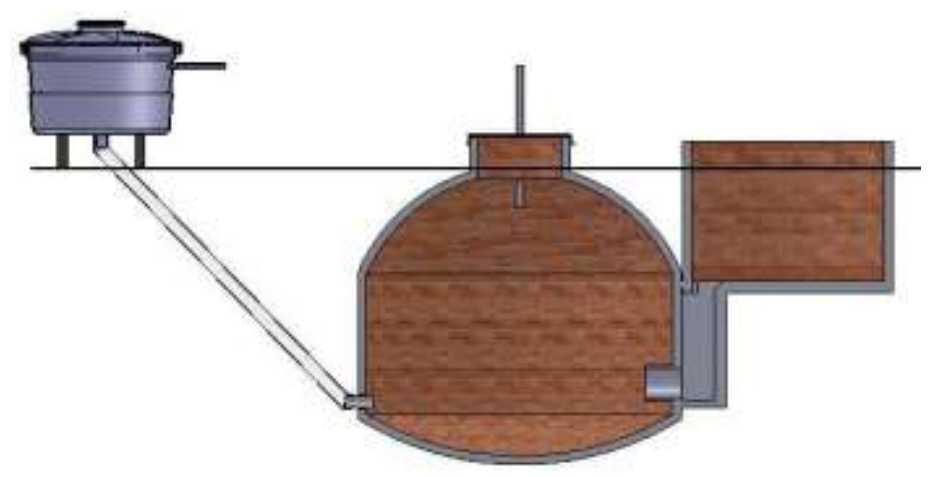

Fonte: Faria (2011).

Para um desenvolvimento econômico e atrativo da digestão da biomassa de resíduos animais é imprescindível que exista uma compatibilidade das características físicas e químicas do resíduo com o projeto de biodigestor selecionado. A escolha do adequado biodigestor, para um resíduo particular, é a chave para um desenvolvimento e processo apropriados. Assim, se faz importante entender os princípios de operação da maioria dos biodigestores para auxiliar na seleção e 
planejamento de um modelo de tratamento a partir da biodigestão anaeróbia. A importância de se ter este conhecimento está relacionado à elevada produção de metano e as taxas de produção de biogás, que são dependentes da relativa contribuição do resíduo e custo do biodigestor para o custo final do biogás (Palhares, 2003).

Conforme cita Faria (2011), existe um terceiro modelo de biodigestor muito utilizado também no Brasil, denominado modelo de fluxo tubular ou biodigestor modelo canadense. Este biodigestor é caracterizado fundamentalmente por uma câmara de fermentação cavada no solo, coberta por uma manta de polietileno de alta densidade (PEAD) na cor preta e revestimento interno feito por material sintético flexível, manta de policloreto de vinila (PVC), nas cores preta ou branca, para evitar possíveis vazamentos e, consequentemente, contaminação do solo e do lençol freático. De modo esquemático, é como uma lagoa retangular coberta, conforme apresentado na Figura 4. Nesse modelo, a cobertura com manta de PVC flexível age como um gasômetro, armazenando o biogás gerado.

Figura 4. Modelo de biodigestor tipo fluxo tubular ((a) Vista longitudinal; (b) Vista Transversal).

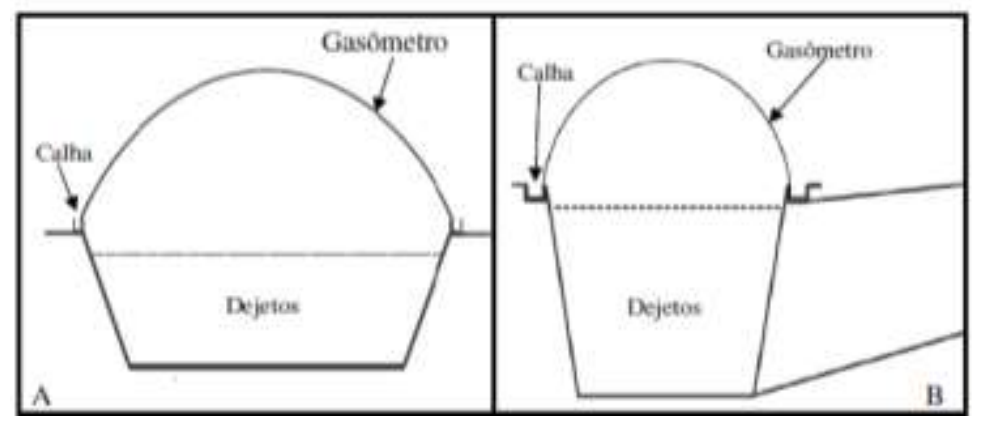

Fonte: Sagula (2012).

Segundo Orrico Júnior et al. (2010), a cama de frango é um resíduo gerado em intervalos de tempo, a disponibilidade não é contínua devido ao modo de produção, ou seja, é um resíduo removido com menor frequência, pois a limpeza diária não é praticada. E considerando suas propriedades físicas e químicas como alto teor de sólidos, baixa umidade e tamanho das partículas, o modelo de biodigestor ideal para a cama, pelas suas características de desenho e desempenho, para uma perfeita digestão anaeróbia da biomassa é o biodigestor batelada, podendo este ser manejado em forma de bateria ou sequencialmente (Deganutti et al., 2004). A desvantagem do manejo em forma de bateria está relacionada à velocidade de fermentação da cama, que é lenta, dificultando o aproveitamento do biogás.

Os biodigestores batelada manejados em bateria, constituem-se basicamente de um corpo cilíndrico, um gasômetro flutuante e uma estrutura para guia do gasômetro. No manejo sequencial, o biodigestor é comprido, horizontal e em seção transversal trapezoidal, a partir da escavação do solo e revestimento de fundo com manta de PVC, constrói-se na superfície uma canaleta de concreto, que atua como selo de água, em torno do biodigestor, e para fixação da manta plástica que serve como gasômetro.

Sendo assim, o emprego dos biodigestores no meio rural tem merecido destaque devido aos aspectos de saneamento e energia, além de estimular a reciclagem orgânica e de nutrientes. $\mathrm{O}$ aspecto saneamento surge quando isolam-se os resíduos do homem e dos animais, proporcionando redução de insetos e odores, permitindo também a redução das demandas química e bioquímica de oxigênio e de sólidos, tornando mais disponíveis os nutrientes para as plantas (biofertilizante), encontrando-se em algumas referências a redução de parasitas e patógenos do homem e dos animais.

Dessa forma, a biodigestão anaeróbia da cama de frangos de corte é uma opção sustentável para o tratamento de resíduos avícolas. Por meio desse processo, o produtor produz um combustível com um alto poder energético, que pode ser utilizado para gerar energia elétrica, térmica ou mecânica a baixo custo, recicla de maneira satisfatória o material residual da 
sua granja e contribui para a diminuição dos impactos ambientais gerados no processo de produção (Aires et al., 2010). Ou seja, o emprego de biodigestores no campo auxilia no desenvolvimento econômico do produtor. O benefício no uso de biodigestores é a viabilidade, principalmente ao se pensar a longo prazo, em que a energia que esta tecnologia gera poderia ser distribuída, ajudando para que diminuam os custos, proporcionando desenvolvimento seguro para o município e garantindo assim, a preservação do meio ambiente e a diminuição dos gases de efeito estufa (Colatto\& Langer, 2011).

\section{Conclusão}

Conclui-se que por meio da biodigestão da cama de frango, é possível produzir combustível para geração de energia a baixo custo, gerenciamento adequado do resíduo da granja, além de colaborar ambientalmente, reduzindo os possíveis impactos ambientais produzidos na atividade avícola se for descartado sem maiores cuidados, além de tornar a atividade um modelo de produção sustentável, sem perda de produção de carne.

Os resultados contribuem para estudos futuros de viabilidade econômica de sistemas combinados e arranjos operacionais de sistemas de tratamento anaeróbio, consolidando um sistema com maior eficiência de tratamento e sustentabilidade energética, permitindo redução de custos operacionais dentro da atividade avícola.

\section{Agradecimentos}

Os autores agradecem ao Instituto de Ciências Agrárias e Ambientais (ICAA), aos Programas de Pós-Graduação em Ciências Ambientais (PPGCAM) e em Zootecnia (PPGZ) da Universidade Federal do Mato Grosso e ao Programa de PósGraduação em Engenharia Agrícola (PPGEA) da Universidade Federal de Campina Grande.

\section{Referências}

Abouelenien, F., Kitamura, Y., Nishio, N., \& Nakashimada, Y. (2009). Dry anaerobic ammonia-methane production from chicken manure. Applied microbiology and biotechnology, 82(4), 757-764.

ABPA - Associação Brasileira de Proteína Animal. 2021. Relatório Anual ABPA. https://abpa-br.org/wp-content/uploads/2021/04/ABPA_Relatorio_Anual_ 2021_web.pdf.

Aires, A. M. A., Lucas Junior, J., Fukayama, H. E., Machado, R. C., \& Guidolin, F. G. D. (2010). Biodigestão anaeróbia da cama de frangos de corte com ou sem separação das frações sólida e líquida sobre a produção de biogás e a qualidade do biofertilizante. Engenharia Agrícola, 30(2), 212-223.

Angelidaki, I., Treu, L., Tsapekos, P., Luo, G., Campanaro, S., Wenzel, H., \& Kougias, P. G. (2018). Biogas upgrading and utilization: Current status and perspectives. Biotechnology advances, 36(2), 452-466.

Aquino, S. F., Chernicharo, C. A. L., Foresti, E., Santos, L., \& Monteggia, L. O. (2007). Metodologias para determinação da atividade metanogênica específica (AME) em lodos anaeróbios. Revista Engenharia Sanitária e Ambiental, 12(2), 92-201.

Arruda, M. H, Amaral, L. P, Pires, O. P. J, \& Barufi, C. R. V. (2002). Dimensionamento de Biodigestor para Geração de Energia Alternativa. Revista científica eletrônica de agronomia, 1(2), 1-8.

Barana, A. C. (2000). Avaliação de tratamento de manipueira em Biodigestores fase acidogênica e metanogênica. Dissertação (Doutorado em Agronomia) Faculdade de Ciências Agronômicas da UNESP - Campus de Botucatu, SP. 105 p.

Batista, S. de P., Guerra, E. P., Resende, J. T. V., Gueri, M. V. D., Carvalho, G. C., Crestani, J. N. S., \& Silva, I.F. L. (2019). Potencial de geração de biogás a partir de genótipos de batata-doce. Revista Ambiente \& Água [online], 14(2), e2317.

Bayrakdar, A., Sürmeli, R. Ö., \& Çalli, B. (2018). Anaerobic digestion of chicken manure by a leach-bed process coupled with side-stream membrane ammonia separation, Bioresource Technology, 258, 41-47.

Bonturi, G. L., \& Dijk, M. V. (2012). Instalação de biodigestores em pequenas propriedades rurais: análise de vantagens socioambientais. Revista Ciências do Ambiente, 8(2), 88-95.

Bortolini, J., Tavares, M. H.F., Freitag, D.T., \& Kuczman, O. (2020). Removal of solids and chemical oxygen demand in poultry litter anaerobic digestion with different inocula. Revista Ambiente \& Água [online], 15(2), e2469.

Brumano, G. (2008). Mercado de carbono e os impactos da avicultura ao meio ambiente. Revista Eletrônica Nutritime, 5(6), p.722-741. 
Caruso, M. C., Braghieri, A., Capece, A., Napolitano, F., Romano, P., Galgano, F., Altieri, G., \& Genovese, F. (2019). Recent Updates on the Use of AgroFood Waste for Biogas Production. Applied Sciences, 9(6):1217.

Catarino, R. P, González, A. P. N, \& Oliveira, L. R. P. (2009). Otimização da produção de metano na biodigestão da cama-de-frango - In: I Simpósio Internacional sobre Gerenciamento de Resíduos de Animais - Geração de Energia a partir de Resíduos Animais - Florianópolis, SC - Brasil.

Chinivasagam, H. N., Estella, W., Rodrigues, H., Mayer, D. G., Weyand, C., Tran, T., Onysk, A., \& Diallo, I. (2016). On-farm Campylobacter and Escherichia coli in commercial broiler chickens: Re-used bedding does not influence Campylobacter emergence and levels across sequential farming cycles. Poultry Science, $95,1105-1115$.

Colatto, L, \& Langer, M. (2011). Biodigestor - resíduo sólido pecuário para produção de energia. Unoesc \& Ciência - ACET, 2(2), 119-128.

Costa, L. V. C. (2012). Produção de biogás utilizando cama de frango diluída em água e em biofertilizante de dejetos de suínos. Tese (doutorado) Universidade Estadual Paulista, Faculdade de Ciências Agronômicas, Botucatu, 75p.

Dalólio, F.S., Silva, J. N. da., Oliveira, A. C. C. de., Tinôco, I. F. F., Barbosa, R. C., Resende, M. O., Albino, L.F. T., \& Coelho, S. T. (2017). Poultry litter as biomass energy: a review and future perspectives. Renewable and Sustainable Energy Reviews, 76, 941-949.

Deganutti, R., Palhaci, M.C.J.P, Rossi, M., \& Tavares, R. (2004). Biodigestores Rurais:Modelos Indiano, Chinês e Batelada. Trabalho apresentado no AGRENER 2004. Departamento de Artes e Representação Gráfica, FAAC - Faculdade de Arquitetura, Artes e Comunicação, UNESP - Universidade Estadual Paulista Julio de Mesquita Filho, Bauru, São Paulo.

Demirci, G. G., \& Demirer, G. N. (2004). Effect of initial COD concentration, nutrient addition, temperature and microbial acclimation on anaerobic treatability of broiler and cattle manure. Bioresource Technology, 93, 109-117.

Dornelas, K.C., Schneider, R.M., \& do Amaral, A.G. (2017). Biogas from poultry waste—production and energy potential. Environ Monit Assess, $189,407$.

Dotto, R. B., \& Wolff, D. B. (2012). Biodigestão e produção de biogás utilizando dejetos bovinos. Disciplinarum Scientia,13(1), 13-26.

El-Mashad, H. M., \& Zhang, R.H. (2010). Biogas production from co-digestion of dairy manure and food waste. Bioresour. Technol., 101, 4021-4028.

Faria, R. L. A. (2011). Geração de energia pela biodigestão anaeróbica de efluentes: o caso da suinocultura. Revista Complexus, 2(3), 28-43.

Fasolin, L. B., Kaveski, I. D. S., Chiarello, T. C., Marassi, R. B., \& Heinn, N. (2014). Relação entre o Índice de Sustentabilidade e os Indicadores Econômicofinanceiros das empresas de energia brasileiras. Revista em Gestão, Educação e Tecnologia, 18(2),955-981.

Font-Palma, C. (2012). Characterisation, kinetics and modelling of gasification of poultry manure and litter: An overview, Energy Conversion and Management, 53(1),92-98.

Freitas, F., Cristina Furtado, A., \& Yegros Cuevas, A. (2018). Construção de um biodigestor didático para a estação ciências do parque tecnológico de Itaipu. Revista Brasileira de Extensão Universitária, 9(2), 65-74.

Garcês, A.P.J.T., Afonso, S.M.S., Chilundo, A., \& Jairoce, C. T. S. (2017). Evaluation of different litter materials for broiler production in a hot and humid environment: 2. Productive performance and carcass characteristics. Tropical Animal Health and Production, 49, 369-374.

Ge, X., Matsumoto, T., Lisa, K., \& Yebo, L. (2014). Biogas energy production from tropical biomass wastes by anaerobic digestion. Bioresource Technology, $169,38-44$.

Gonçalves, F. da S., \& Ramalho, A. R. dos S. (2021). Biodigestão anaeróbia da manipueira gerada na casa de farinha no município de Branquinha/AL, Brasil. Diversitas Journal, 6(1), 36-47.

Gyenge, L., Ráduly, B., Crognale, S., Lányi, S., \& Ábrahám, B. (2014). Cultivating conditions optimization of the anaerobic digestion of corn ethanol distillery residuals using response surface methodology. Central European Journal of Chemistry, 12(3), 868-876.

Hajjaji, N., Martinez, S., Trably, E., Steyer, J. P., \& Helias, A. (2016).Life cycle assessment of hydrogen production from biogas reforming, International Journal of Hydrogen Energy, 41( 14), 6064-6075.

Holm-Nielsen, J. B., Al Seadi, T., \& Oleskowicz-Popiel, P. (2009). The future of anaerobic digestion and biogas utilization. Bioresource Technology, 100(22), 5478-5484.

Jorge, L. H. A., \& Omena, E. (2012). Biodigestor. Dossiê Técnico. SENAI/AM - Escola SENAI Antônio Simões.

Kohn, M. P., Castaldi, M. J., \& Farrauto, R. J. (2014). Biogas reforming for syngas production: The effect of methyl chloride. Applied Catalysis B: Environmental, 144, 353-361.

Leite V. D., Lopes, W. S., Sousa, J. T., Prasad, S., \& Silva, S. A. (2009). Tratamento anaeróbio de resíduos sólidos orgânicos com alta e baixa concentração de sólidos. Revista Brasileira de Engenharia Agrícola e Ambiental, 13(2), 190-196.

Luste, S., Heinonen-Tanski, H., \& Luostarinen, S. (2012). Co-digestion of dairy cattle slurry and industrial meat-processing by-products: effect of ultrasound and hygienization pre-treatments. Bioresource Technology, 104, 195-201.

Martins, S. D, \& Assis, G. E. (2007). Estudo da viabilidade econômica da implantação de um biodigestor em uma granja de perus - In: XXVII Encontro Nacional de Engenharia de Produção - Foz do Iguaçu, PR, Brasil.

Metz, H. L. (2013). Construção de um biodigestor caseiro para demonstração de produção de biogás e biofertilizante em escolas situadas em meios urbanos. Trabalho de conclusão de Curso (Graduação) - Universidade Federal de Lavras, curso de Pós-Graduação Lato Sensu em Formas Alternativas de Energia. LAVRAS - MG. 
Neto, E. D. D., Alvarenga, L. H., Costa, L. M., Nascimento, P. H., Silveira, R. Z., \& Leite, L. H. M. (2010). Implementação e avaliação de um biodigestor de produção descontínua. Revista Exacta, 3(2),36-43.

Nges, I. A., \& Liu, J. (2010). Effects of solid retention time on anaerobic digestion of dewatered-sewage sludge in mesophilic and thermophilic conditions. Renewable Energy, 35, 2200 - 2206.

Nie, H., Jacobi, H. F., Strach, K., Xu, C., Zhou, H., \& Liebetrau, J. (2015). Mono-fermentation of chicken manure: Ammonia inhibition and recirculation of the digestate. Bioresource Technology, Amsterdam, 178,238- 246.

Nutiu, E. (2014). Anaerobic purification installation with production of biogas and liquid fertilizers. Procedia Technology, $12,632-636$.

Okudoh, V. Trois, C. Workneh, T. \& Schidt, S. (2014). The potential of cassava biomass and applicable technologies for sustainable biogas production in South Africa: A review. Renewable and Sustainable Energy Reviews, 39, 1035-1052.

Oliveira, A. B. de, M., Orrico, A. C. A., Orrico Júnior, M. A. P., Sunada, N. da, S., \& Centurion, S. R. (2011). Biodigestão anaeróbia de efluente de abatedouro avícola. Revista Ceres, 58(6), 690-700.

Oliveira, A. J, \& Ramalho, J. (2006). Plano Nacional de Agroenergia 2006-2011 - Ministério da Agricultura, Pecuária e Abastecimento, Secretaria de Produção e Agroenergia. 2. ed. rev. - Brasília, DF: Embrapa Informação Tecnológica, 110 p.

Oliveira, L. G., Freitas, D. C. de., Batalha, M. O., \& Alcântara, R. L. C. (2015). Gerenciamento de riscos na cadeia agroindustrial de frango: análise da perspectiva dos avicultores em ubá, Minas Gerais. Revista Produção Online, 15(4), 1305-1325.

Orrico Júnior, M. A. P., Orrico, A. C. A., Lucas Júnior, J. de, Sampaio, A. A. M., Fernandes, A. R. M., \& Oliveira, E. A. de. (2012). Biodigestão anaeróbia dos dejetos da bovinocultura de corte: influência do período, do genótipo e da dieta. Revista Brasileira de Zootecnia, 41(6), 1533-1538.

Orrico Júnior, M. A. P, Orrico, A. C. A, Lucas Júnior, J. (2010). Biodigestão anaeróbia dos resíduos da produção avícola: cama de frangos e carcaças. Eng. Agríc.,30(3), 546-554.

Paiva, E. C. R., Matos, A. T., Azevedo, M. A., Barros, R. T. P. De, \& Costa, T. D. R. (2012). Avaliação da compostagem de carcaças de frango pelos métodos da composteira e de leiras estáticas aeradas. Engenharia Agrícola, Jaboticabal, 32(5), 961-970.

Palhares, P. C. J. (2003). Uso de biodigestores para o tratamento da cama de frango: conceitos importantes para a produção de biogás - Pesquisador da Embrapa Suínos e Aves. Circular Técnica - Área de avaliação de impacto e gestão ambiental.

Pasqualini, A. A. (2020). Aplicação dos biodigestores na pecuária sustentável. Revista Faculdades do Saber, 5(9), 598-609.

Patel, S. K. S., Madina, P., Kim, D., Kim, S.-Y., Kalia, V. C., Kim, I.-W., \& Lee, J.-K. (2016). Improvement in methanol production by regulating the composition of synthetic gas mixture and raw biogas. Bioresource Technology, 218, 202-208.

Paula Junior, S. E. M. Avaliação das Alternativas de Disposição Final do Resíduo da Produção de Frango de Corte: Cama de Frangol - Rio de Janeiro: Ufrj/Escola Politécnica, 2014.

Penteado, M., de Lima, G., Zarpellon, F., Gueri, M., \& Schirmer, W. (2021). Potencial energético do biogás gerado a partir da biodigestão de resíduos do processamento industrial de erva-mate. Revista aidis de ingeniería y ciencias ambientales. Investigación, 14(2), 767-785.

Pereira, A. S., Shitsuka, D. M., Parreira, F. J. \& Shitsuka, R. (2018). Metodologia da pesquisa científica. UFSM.

Perondi, D., Poletto, P., Restelatto, D., C., Silva, J. P., Junges, J., Collazzo, G. C., Dettmer, A., Godinho, M., \& Vilela, A. C. F. (2017). Steam gasification of poultry litter biochar for bio-syngas production, Process Safety and Environmental Protection, 109, 478-488.

Procópio, D. P., \& Lima, H. J. D. (2020). Poultry production conjecture in Brazil. Research, Society and Development, 9(3), e47932312.

Purnomo, C. W., Indarti, S., Wulandari, C., Hinoded, H., \& Nakasaki, K. (2017).Slow Release Fertiliser Production from Poultry Manure. Chemical Engineering Transactions,56, 1531-1536.

Rao, P. V., \& Baral, S.S. (2011). Experimental design of mixture for the anaerobic co-digestion of sewage sludge. Chem. Eng., 172, 977-986.

Reck, A. B., \& Schultz, G. (2016). Aplicação da metodologia multicritério de apoio à decisão no relacionamento interorganizacional na cadeia da avicultura de corte. Rev. Econ. Sociol. Rural, 54(4), 709-728.

Rêgo, J. O., Brandão, M. C.P., Torres Neto, A. B., \& Cavalcanti, L. A. P. (2021). Análise da viabilidade de geração de energia e produção de biofertilizantes a partir de dejetos de animais em uma fazenda no Sul da Bahia. Brazilian Journal of Development, 7(7), 75312-75329.

Ribeiro, E. M., Mambeli Barros, R., Tiago Filho, G. L., dos Santos, I. F. S., Sampaio, L. C., dos Santos, T. V., da Silva, F. G. B., Silva, A. P. M., \& de Freitas, J. V. R. (2018). Feasibility of biogas and energy generation from poultry manure in Brazil. Waste Management \& Research, 36(3), $221-235$.

Ribeiro, S. A. dos S., Junho, A. L., Barros, R. M., Santos, I. F. S. dos, Filho, G. L. T., Martuscelli, E., \& Freitas, J. V. R. de. (2020). Preliminary study of biodigestion of bovine manure with whey in the double-stage digestion system with biogas purification. Research, Society and Development, 9(8), e646985911.

Rieze, J. De, Raport, L., Willems, B., Verbrugge, S., Volcke, E., Meers, E., Angenent, L. T., \& Boon, N. (2015). Inoculum selection influences the biochemical methane potential of agro-industrial substrates. Microbial Biotechnology, 8, 776-786.

Sagula, A. L. (2012). Biodigestão anaeróbica de cama de frango em co-digestão com caldo de cana-de-açúcar. Dissertação (mestrado) - Universidade Estadual Paulista, Faculdade de Ciências Agronômicas, Botucatu, 56p. 
Sagula, A. L., Costa, L. V. C., \& Junior, J. L. (2017). Diferentes diluições e uso de reciclo na biodigestão anaeróbia de cama de frango triturada e peneirada: ensaio batelada. Brazilian Journal of Biosystems Engineering, 11(4), 373-384.

Santos, T. M. B. dos. (2021). Balanço energético e adequação do uso de biodigestores em galpões de frangos de corte. Tese (Doutorado em Produção Animal) - Faculdade de Ciências Agrárias e Veterinárias, Universidade Estadual Paulista, Jaboticabal, 167 p.

Santos, T. M. B, \& Lucas Júnior, J. (2004). Balanço energético em galpão de frangos de corte. Engenharia Agrícola, 24(1), 25-36.

Schmidt, N. S., \& Silva, C. L.da. (2018). Pesquisa e Desenvolvimento na Cadeia Produtiva de Frangos de Corte no Brasil. Revista de Economia e Sociologia Rural, 56(3), 467-482.

Seman, S. Z. A., Idris, I., Abdullah, A., Shamsudin, I. K., \& Othman, M. R. (2019). Optimizing purity and recovery of biogas methane enrichment process in a closed landfill. Renewable Energy, 131,1117-1127.

Shen, J., \& Zhu, J. (2016). Optimization of methane production in anaerobic co-digestion of poultry litter and wheat straw at different percentages of total solid and volatile solid using a developed response surface model. Journal of Environmental Science and Health, 51(2), $325-334$.

Silva, C. E. D. F., \& Abud, A. K. D. S. (2017). Influence of manure concentration as inoculum in anaerobic digestion of vinasse. Acta Scientiarum. Biological Sciences, 39(2), 173+.

Silva, C. O., Cezar, V. R. S., Santos, M. B., \& Santos, A. S. (2013). Biodigestão Anaeróbia com substrato formado pela combinação de esterno ovinocaprino, manipueira e biofertilizante. Revista Ibero-Americana de Ciências Ambientais, 4(1), 88 - 103.

Singh, R., Krishna, B. B., Kumar, J., \& Bhaskar, T. (2016). Opportunities for utilization of non-conventional energy sources for biomass pretreatment. Bioresour Technol, 199:398-407.

Steil, L, Lucas Junior, J, \& Oliveira, R. A. (2002). Avaliação do uso de inóculo na digestão anaeróbia de resíduos de aves de postura, frangos de corte e suínos. Engenharia Agrícola, 22(2), 146-159.

Sunada, N. da. S., Orrico, A. C. A., Orrico Júnior, M. A. P., Vargas Junior, F. M. de, Garcia, R. G., \& Fernandess, A. R. M. (2012). Potential of biogas and methane production from anaerobic digestion of poultry slaughterhouse effluent. Revista Brasileira de Zootecnia, 41(11), 2379-2383.

Suzuki, A. B. P., Feiden, A., Ernandes, D. M., Martins, G. I., \& Faria, R. A. P. (2012). Utilização de manipueira juntamente com sólidos da cama de aviário em biodigestores para geração de biogás. Ambiência - Revista do Setor de Ciências Agrárias e Ambientais, 8(3), 809-820.

Suzuki, A. B. P., Fernandes, D. M., Faria, R. A. P., \& Souza, S. N. M de. (2014). Produção de biogás em escala real em unidade demonstrativa - Unidade Granja Colombari. Ambiência - Revista do Setor de Ciências Agrárias e Ambientais, 10(1),13 - 20.

Taupe, N. C., Lynch, D., Wnetrzak, R., Kwapinska, M., \& Kwapinski, J. J. W. (2016). Leahy, Updraft gasification of poultry litter at farm-scale - A case study, Waste Management, 50, 324-333.

Tessaro, A. B., Tessaro, A. A., Cantão, M. P., \& Mendes, M. A. (2015). Potencial energético da cama de aviário produzida na região sudoeste do Paraná e utilizada como substrato para a produção de biogás. Revista em Agronegócio e Meio Ambiente, 8(2), 357-377.

Tremea, F. T., \& Silva, A. C. (2020) O setor avícola no Brasil e sua distribuição regional. Economia \& Região, 8(1),183-200.

Trevizan, P. S. F. (2013). Produção de biogás por dejetos de suínos em terminação suplementados com ractopamina. Aquidauana, MS, UEMS. Dissertação (Mestrado) - Zootecnia - Universidade Estadual de Mato Grosso do Sul, 54p.

Virtuoso, M. C. da, Silva., Oliveira, D. G. de, Dias, L. N. de, S., Fagundes, P. S. de, F., \& Leite, P. R. de, S. da, C. (2015). Reutilização da Cama de Frango. Revista Eletrônica Nutritime, 12(02), 3964-3979.

Wicks, M, Dangaran, K, \& Beartshce, S. (2013). Manure Processing Technologies. Anaerobic Digestion. The Ohio State University, 3,1-11.

Xavier, C. A. N., \& Lucas Junior, J. (2010). Parâmetros de dimensionamento para biodigestores batelada operados com dejetos de vacas leiteiras com e sem uso de inóculo. Engenharia Agrícola, 30(2), 212-223.

Zeb, I., Jingwei, M., Craig, F., Quanbao, Z., Pius, N., Yiqing, Y., \& Gopi Krishna, K. (2017). Recycling separated liquid-effluent to dilute feedstock in anaerobic digestion of dairy manure. Energy, 119, 1144-1151.

Zhang, T., Yang, Y., Liu, L., Han, Y., Ren, G., \& Yang, G. (2014). Improved biogas production from chicken manure anaerobic digestion using cereal residues as cosubstrates. Energy \& Fuels, 28(4), 2490-2495. 